\title{
THE RELATIONSHIP OF PULMONARY COMPLIANCE TO PULMONARY VASCULAR PRESSURES IN PATIENTS WITH HEART DISEASE ${ }^{1}$
}

\author{
By GEORGE A. SAXTON, JR., ${ }^{2}$ MURRAY RABINOWITZ, ${ }^{3}$ LEWIS DEXTER, AND \\ FLORENCE HAYNES WITH THE TECHNICAL ASSISTANCE OF CONSTANCE WALKER
}

\begin{abstract}
(From the Medical Service, Peter Bent Brigham Hospital and the Department of Medicine, Harvard Medical School, Boston, Mass.)
\end{abstract}

(Submitted for publication December 12, 1955 ; accepted February 15, 1956)

The mechanisms of dyspnea in congestive heart failure, although intensively investigated, have yet to be completely elucidated. Cardiac dyspnea has long been attributed to structural or functional changes in the lungs secondary to cardiac failure. Morphological alterations were first described by the pathologists of the 19 th century. More recently, in the 20th century, this morphological approach has been complemented by determinations of pulmonary function during life.

Prominent among the early observations of functional impairment were Peabody and Wentworth's correlation of cardiac dyspnea with decreased vital capacity (1), followed by Christie and Meakins' measurement of increased excursions of intrapleural pressure in heart failure (2), and the demonstration in experimental animals that pulmonary vascular congestion reduces pulmonary distensibility $(3,4)$. In vivo estimations of pulmonary blood volume in heart disease, however, have failed to demonstrate the expected correlations between increasing pulmonary vascular volume, increasing pulmonary vascular pressures and dyspnea (5-7). The limitations of existing methods may be responsible. Recently, emphasis has been placed upon the quantitative evaluation of the elastic properties of the lung in relation to cardiac dyspnea $(8,9)$. These studies have shown

1 This work was supported in part by grants from the Life Insurance Medical Research Fund and the National Heart Institute, U. S. Public Health Service (grant No. $\mathrm{H}-450$ ).

2 This work was done during the tenure of a Postdoctorate Fellowship from the National Heart Institute, U. S. Public Health Service. Present Address: University of Illinois, College of Medicine, 840 South Wood St., Chicago 12, Illinois.

3 This work was done during the tenure of a Postdoctorate Fellowship from the National Heart Institute, U. S. Public Health Service. Present Address: Institute for Enzyme Research, University of Wisconsin, 1702 University Ave., Madison, Wisconsin. that the distensibility of the lungs, designated pulmonary compliance, is consistently reduced in the presence of cardiac dyspnea. Furthermore, this reduction of pulmonary compliance has been shown to be associated with increased work of breathing in the presence of mitral stenosis (10). This factor of compliance has also been studied in emphysema and other primary lung diseases by other groups of workers over the same period (11-14). More recently, new techniques and instruments have been introduced by Mead and Whittenberger (15) and DuBois, Botelho, and Comroe (16) which permit the plotting of changes of intrapleural pressure against changes in pulmonary gas volume on a coordinate system from breath to breath. A modification and simplification of this methodology was developed for this study to facilitate measurement of pulmonary compliance in patients with heart disease during cardiac catheterization. This approach permitted the simultaneous measurement of pulmonary vascular pressures and pulmonary compliance, which had not been possible previously. It was hoped that a study of their dynamic relationships during rest, exercise, and recovery would contribute to a better understanding of the dyspnea of heart disease.

\section{METHODS}

The principal modifications of the Mead technique that became necessary for this study were the substitution of a recording spirometer for the electrically integrated pneumotachograph and the elimination of direct, oscillographic recording. This enabled all the equipment to be assembled on a mobile cart, permitting one person to operate it on the hospital wards or during cardiac catheterization in the laboratory (Figure 1).

One of the most crucial problems in the determination of pulmonary compliance is the accurate measurement of changes in intrapleural pressure. On the basis of observations made by Buytendijk (17), Mead and Gaensler (18), Fry and his co-workers (19) and Cherniack, Farhi, Armstrong, and Proctor (20), intraesophageal pressure 


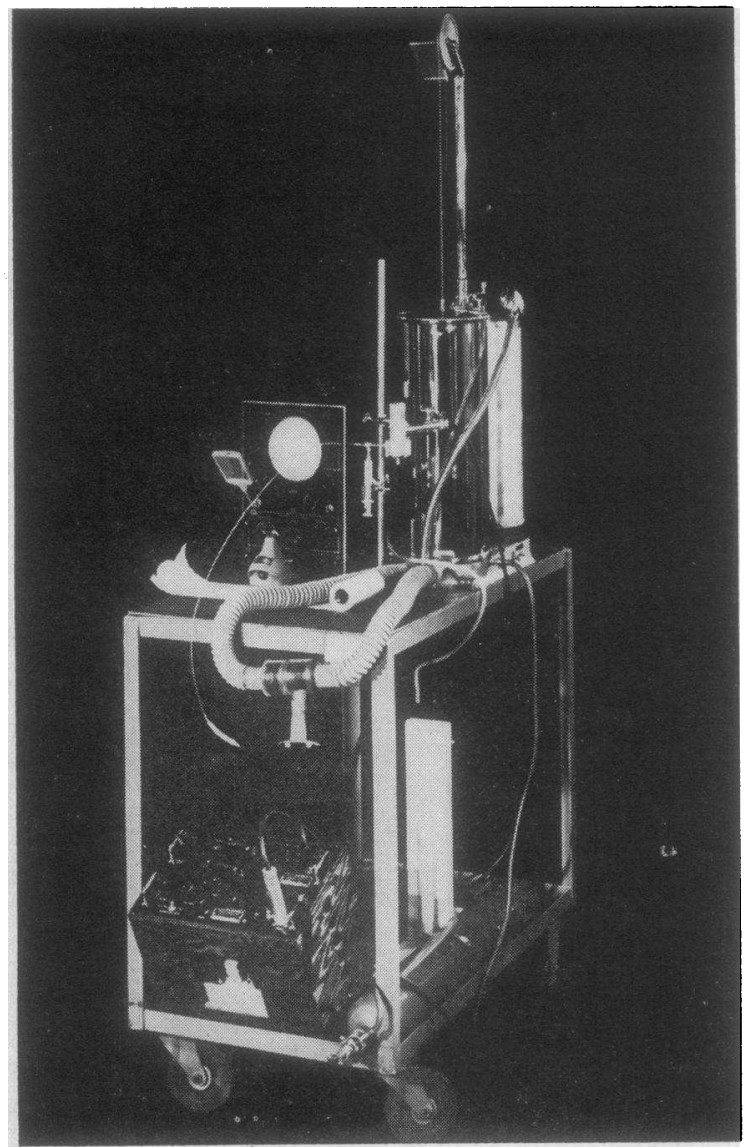

Fig. 1. Mobile Assembly of Equipmext for Measuring Pulmonary Compliance

The esophageal balloon is hanging beside the mouthpiece and valve housing in the foreground.

changes were assumed to reflect intrapleural pressure changes over the surface of the lungs. Changes in intraesophageal pressure were detected by a small balloon sealed over the end of a $63-\mathrm{cm}$. length of fine polythene tubing. This could be passed through one nostril into the esophagus without significant difficulty in most subjects (Figures 1 and 2). The proximal end of the tubing was attached to a relatively sensitive Statham strain gage $(0-5 \mathrm{~cm} . \mathrm{Hg}, 12$ volts maximal). The strain gage was filled with water to within $1 / 2 \mathrm{cc}$. of its capacity, the rest of the balloon and tube system being air-filled. This arrangement served to minimize the volume of air which must shift back and forth in the system with changes in pressure gradient during breathing. The small volume used and the small magnitude of intraesophageal pressure changes reduced the compressibility of gas to an insignificant factor. The strain gage was coupled to a carrier amplifier ${ }^{4}$ mounted in a simple vented box on the lower shelf of the cart. The output

4 Sanborn Company, 39 Osborn Street, Cambridge, Massachusetts. of this amplifier was applied to the vertical plates of an oscilloscope, in such a way that changes in balloon pressure would produce horizontal deflections of the electron beam.

Changes in the gas volume of the lungs were measured by connection of a 6-liter spirometer to the patient's airway by means of large corrugated tubing $(3-\mathrm{cm}$. in diameter), low resistance "Japanese" valves and a mouth-piece. The soda-lime cannister and valves were removed from the spirometer to minimize resistance to air flow in the system. Such an arrangement permitted recording not only of the tidal volume from breath to breath, but also shifts in midposition which might take place during a study. However, the spirometer had to be flushed after 2-3 minutes of use with 100 per cent $O$. to prevent significant $\mathrm{CO}_{2}$ accumulation. Volume changes in the spirometer were converted into electrical terms by the use of a low-torque potentiometer. It was coupled to the wheel of a spirometer and wired as a variable voltage divider across a 1.5 -volt dry cell. Its output was introduced into a DC amplifier ${ }^{4}$ arranged in the same box and in a similar fashion as the carrier amplifier on the lower shelf of the cart. This amplifier's output was coupled directly to the horizontal plates of the oscilloscope. In this way volume changes, converted into variable voltage and amplified, governed the vertical deflections of the electron beam in the oscilloscope.

The oscilloscope used was a Dumont No. 207 with a "long-persistence" screen. The accelerating voltage was eliminated in order to achieve sensitivity of 60 volts per inch, and none of its AC amplifiers was used. Manual tracing of the looped patterns representing the pressurevolume relationships of the lungs was facilitated by the use of a semi-reflecting, semi-transmitting glass. ${ }^{5}$ This was oriented at a $45^{\circ}$ angle before the oscilloscope tube face and above the paper on which the image of the electronbeam loci were to be projected and traced (Figure 2).

A typical record of tracings of "pressure-volume loops" during cardiac catheterization is reproduced in Figure 3. The slope of each family of loops, resulting from breaths of different depths, is indicated by the straight line running through the maximum and minimum volume points of each loop. These are the points of zero air-flow in each respiratory cycle when dynamic factors are not operative, and only the static, predominantly elastic, components of the system are being measured. These points represent the instants of zero air-flow at the end of inspiration and expiration. The pressure gradients across the lungs at these instants, therefore, are only those required to hold the lungs at these volumes. In this way the elastic quality of the lungs, compliance, is evaluated free of dynamic factors such as viscosity of flowing air or tissue. The slope of the line between these points, then, is an expression of pulmonary compliance as calculated in liters of air moved per centimeter of water pressure gradient. (These calculations are shown below each group of loops, ranging from .104 down to .098 when

5 Oscillotracer, Robert Waters Company, Watertown, Massachusetts. 


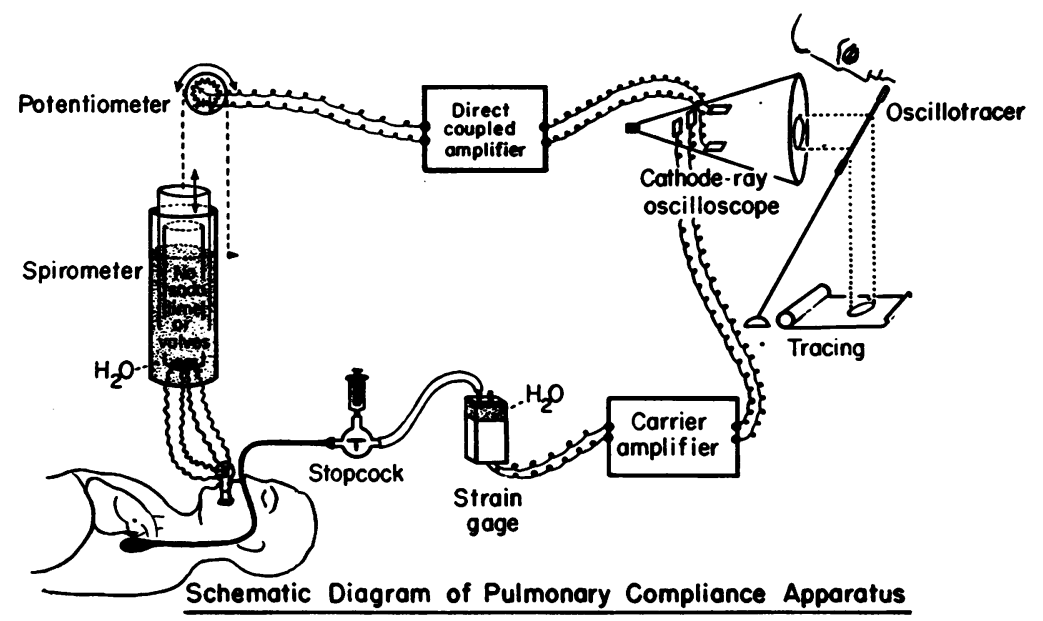

FIG. 2

mean "pulmonary capillary" pressure, "PCm," was 16 to $14 \mathrm{~mm}$. $\mathrm{Hg}$ ).

Calibration of the pressure-recording system was performed with a simple water manometer and the volumerecording system was calibrated by use of the usual spirometer scale. These calibrations were found to be stable over a period of a few hours, checking before and after experiments. They remained linear within the ranges required for this study. Pressure sensitivity, controlled electronically as "gain," was variable so that the pressure-volume loops of normal subjects could be recorded in such a way that their slope could be accurately measured and compared with those encountered in disease states.

The technique used for exercising the patients was largely as described by Dexter, Haynes, Burwell, Eppinger, Seibel, and Evans (21). The patient remained supine, as when at rest, merely raising his legs so as to place his feet on the pedals of an army field generator at the foot of the fluoroscope table. This procedure permitted the simultaneous recording of mean pulmonary "capillary" pressure and pulmonary compliance during rest, exercise, and recovery.

Catheterization of the pulmonary artery, for the recording of pulmonary arterial and pulmonary "capillary" pressures, respectively, was performed via a median basilic vein and the right heart in the manner described by Hellems, Haynes, and Dexter (22). Continuous records of pulmonary "capillary" mean pressure were made via a cardiac catheter in patients at rest, during exercise and after recovery by means of a capacitance manometer using an electronic integrator. ${ }^{4}$ Efforts were made to satisfy the three criteria of Hellems, Haynes, and Dexter (22) before and after measurements of "PC" pressure. If they could not be satisfied, the pressures measured in the pulmonary artery wedge position were not accepted as reflecting true pulmonary "capillary" pressure.

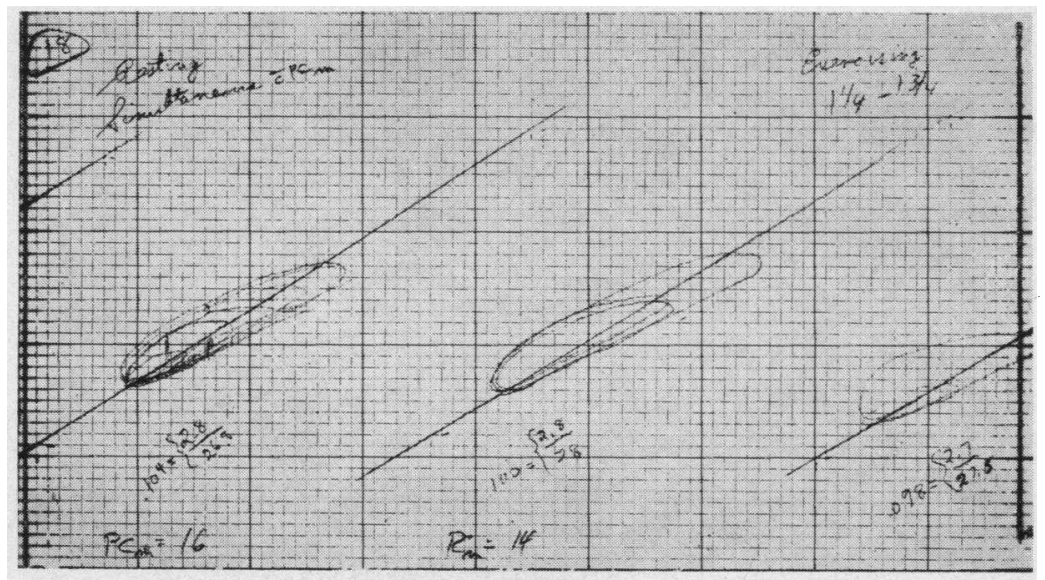

Fig. 3. Typical Tracings of "Pressure-Volume Loops"

Volume is represented on the $y$ axis, pressure on the $x$ axis. 


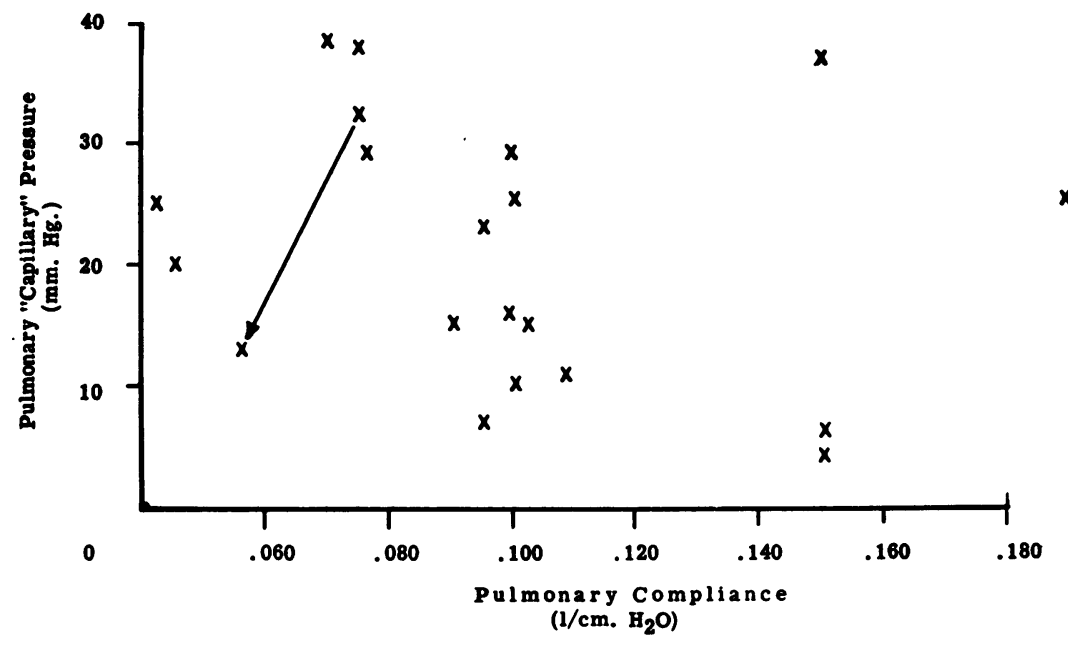

Fig. 4. Relationship of Pulmonary Compliance to Pulmonary "Capillary" Pressure in 19 Cardiac Patients

The arrow designates the change in this relationship which followed mitral commissurotomy in one case.

\section{RESULTS}

Initially, pulmonary compliance was measured in seven patients being considered for cardiac surgery. Their pulmonary compliance was found to be consistently below the normal values for subjects of comparable height and age. The range of compliance among these patients was .05 to .13 L. per $\mathrm{cm} . \mathrm{H}_{2} \mathrm{O}$ pressure gradient across the lungs. On the basis of these findings, eight more preoperative patients were studied by both the cardiac catheter and esophageal balloon to determine whether or not there existed a correlation between pulmonary "capillary" ("PC") pressure and pulmonary compliance. As is illustrated in Figure 4, no clear relationship between the degree of elevation of "PC" pressure and reduction of pulmonary compliance was found.

Also, no better quantitative relationship was found when pulmonary artery pressures were plotted against compliance. In fact, when the data

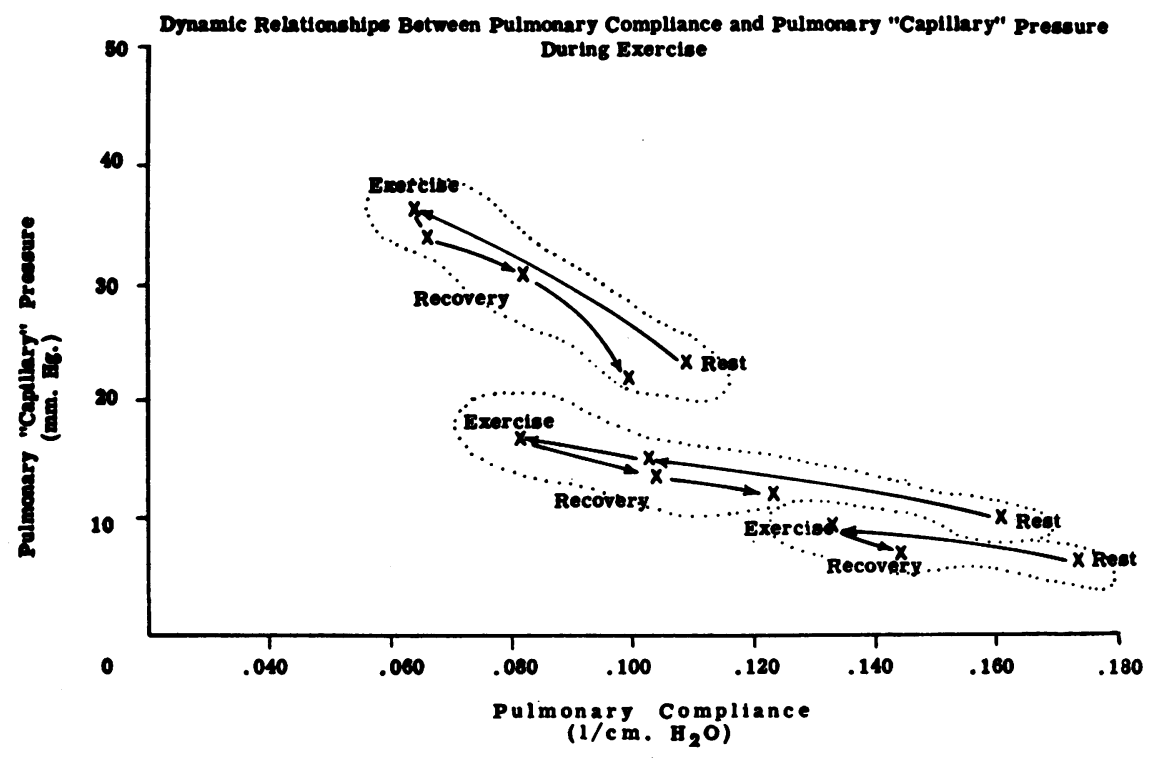

FIG. 5 


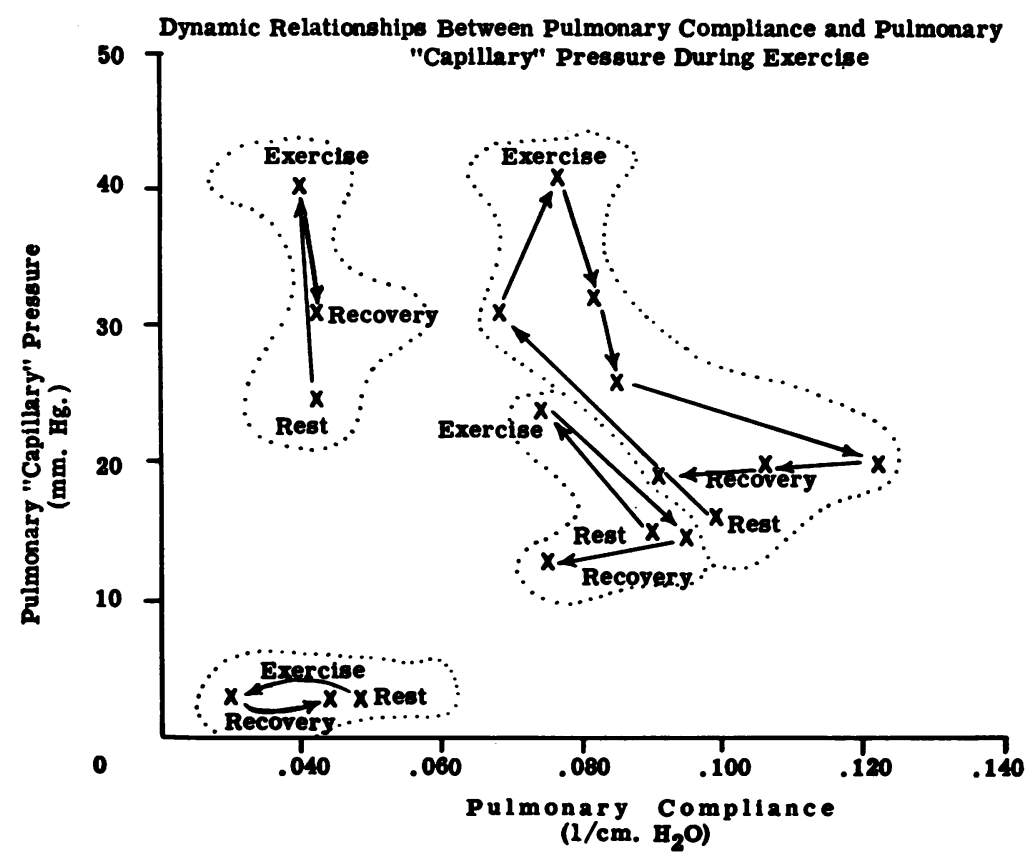

Fig. 6

of one patient before mitral valvulotomy were compared with those after operation, decreased compliance was noted in association with decreased "PC" pressure. (This is indicated by the arrow in Figure 4.)

Further comparisons of compliance measured preoperatively with that measured postoperatively in four additional patients revealed decreased values within two weeks after the surgery. Pulmonary vascular pressures were not obtained in these cases, but the relief of their dyspnea was dramatic within this early postoperative period. Previous studies of "PC" pressures before and after surgery have revealed significant reduction

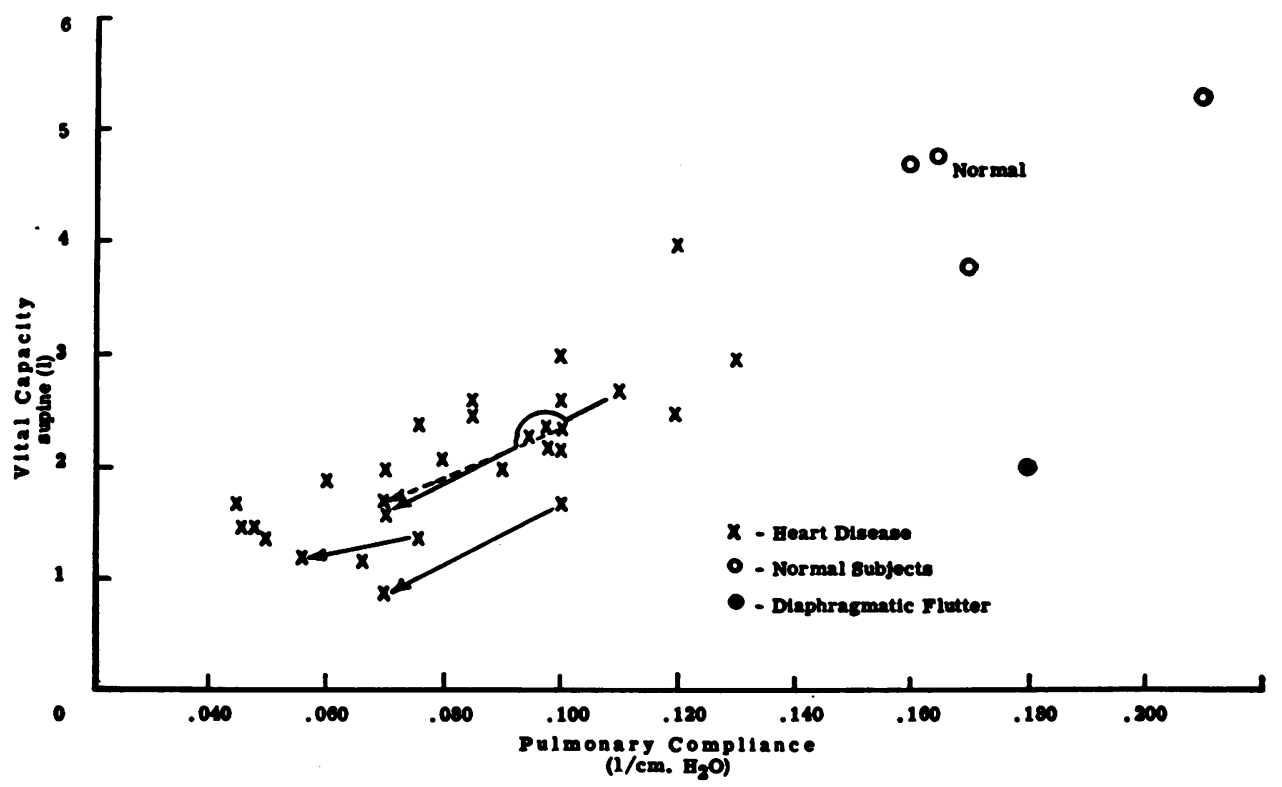

Fig. 7. Relationship of Pulmonary Compliance to Vital Capacity (Arrows Indicate Changes after Valvulotomy) 
in most cases obtaining subjective relief of dyspnea postoperatively (23).

These data did not bear out the assumption that lungs subjected to lower vascular pressures postoperatively would be more compliant. Therefore, a more direct approach was undertaken to clarify the dynamic relationships between compliance and pulmonary vascular pressure. Simultaneous measurement of "PC" pressure and pulmonary compliance during rest, exercise, and recovery were made in ten patients. Figure 5 illustrates three patients in whom the relationship was clearly one of decreasing compliance with increasing "PC" pressure during three minutes of exercise and the reverse during five minutes of recovery. However, this dynamic relationship was not so clear in the cases illustrated in Figure 6. Here it is seen that compliance may decrease or remain unchanged in the face of elevated "PC" pressure.

These data suggested the strong possibility that other factors were involved in addition to changes in pulmonary vascular pressures. No more consistent relationship was found when pulmonary blood flow or pulmonary arteriolar resistance were plotted against compliance. However, a consistent relationship was obtained when vital capacity was plotted against compliance (Figure 7 ). There is not only the rather consistent relationship from one patient to another but the changes after mitral valve surgery follow much the same regression line. This may be expressed simply as the fact that the compliance of the lungs of these patients decreased by $.037 \mathrm{~L}$. per $\mathrm{cm} . \mathrm{H}_{2} \mathrm{O}$ as the vital capacity decreased one liter.

\section{DISCUSSION}

On the basis of these results and the findings of others it may be postulated that pulmonary compliance depends on several factors: 1) It is proportionately related to the height or body surface area of the individual under study (24). This is probably because the lungs of larger people are themselves larger and therefore contain a greater quantity of elastic tissue. Just as a long rubber band stretches more than a short one of the same

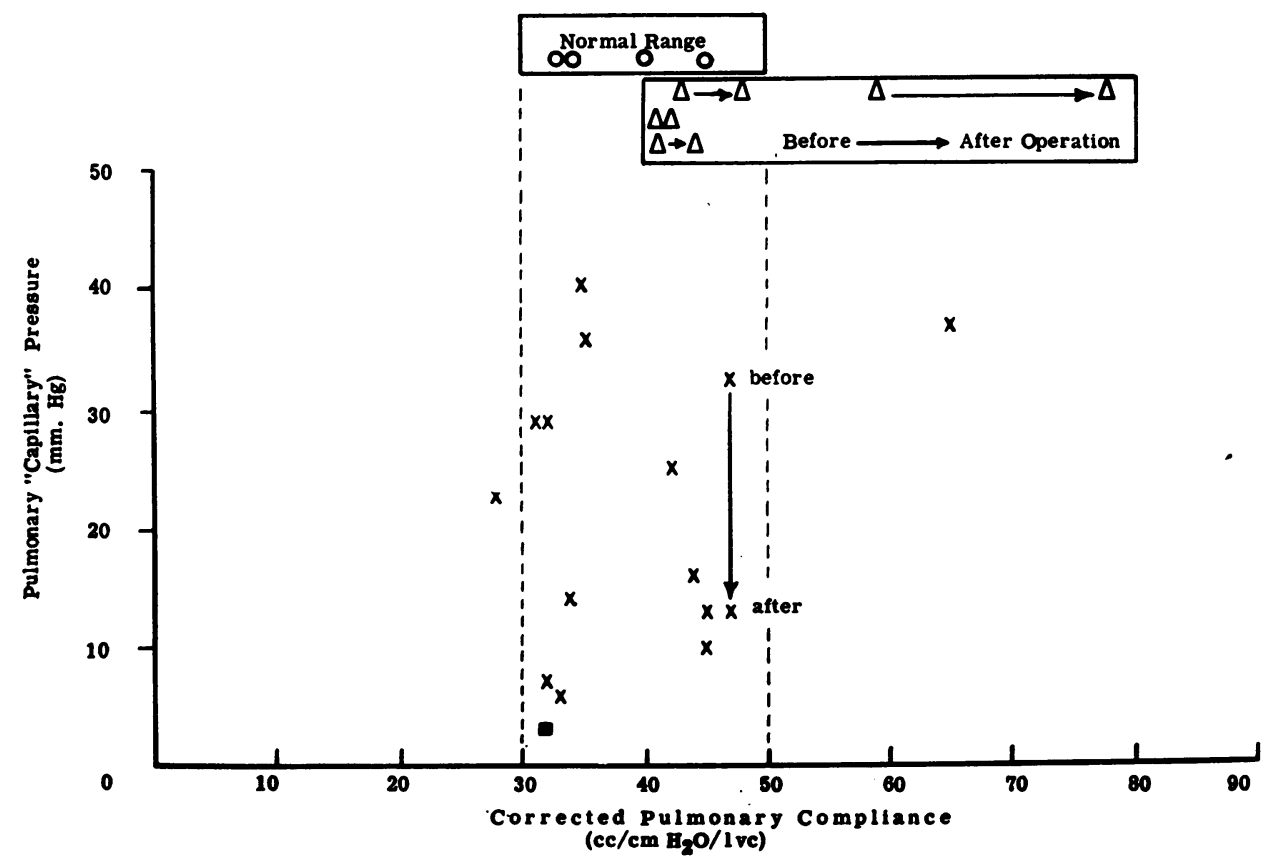

Fig. 8. Relationship of Pulmonary Compliance, "Corrected" for Vital Capacity, to Pulmonary "Capillary" Pressures in 14 Cardiac Patients $(X)$

The normal ranges of "corrected" pulmonary compliance is depicted at the top (O) and projected downward. The effect of mitral commissurotomy is depicted by the arrows in four uncatheterized cases $(\triangle)$ and one case in whom "PC" pressure was measured $(X)$. One case of pulmonary granulomatosis of unknown etiology is included ( $\square$ ). 
material when a given weight is suspended from it, to the same extent larger lungs with more elastic fibers in series can be expected to stretch more when a given transpleural force is applied to them.

2) Pulmonary compliance must be a function of the quality of the elastic components of the lungs and the enveloping pleura. Therefore, damage or deterioration of the intra-pulmonary elastic fibers or thickening of the pleura would be reflected in the necessity for a greater pressure gradient across the lungs to move a given quantity of air into the lungs.

3) Pulmonary compliance may be related in some way to the available quantity of elastic tissue. That is, a certain amount of elastic tissue may be present in the lungs but unavailable in disease states such as congestive failure. It is postulated that this third factor is an important determinant of pulmonary compliance in heart disease on the basis of the foregoing results.

Pulmonary hypertension and reduced pulmonary compliance were found in all the cases studied, though there was no consistent quantitative relationship between the two. The vital capacities, however, were all reduced below normal and to a degree directly proportional to the reduction in compliance. Therefore, it is possible that whatever reduces the vital capacity of the lungs does so by making less elastic tissue available, thereby reducing compliance. This would seem to be supported by the fact that compliance of patients divided by their respective vital capacities yielded quotients in the normal range of such quotients (Figure 8). Thus, pulmonary compliance may be "corrected" for lung volume in such a way that the intrinsic elastic properties of lungs of different sizes can be compared with each other.

On the other hand, it is possible that a qualitative change of the elastic components of the lungs may have reduced the pulmonary compliance and thereby, vital capacity. The calculation suggested for correcting for volume changes would then compensate only for the deterioration of the intrinsic elastic components of the lungs. At present we have no way of knowing which factor is cause, and which effect. However, the reduction of compliance with elevation of "PC" pressure during exercise in some of the cases is suggestive. When this dynamic relationship occurs it seems more likely that less elastic tissue is available in the presence of pulmonary hypertension than that the quality or quantity of elastic tissue in the lung changes with vascular pressure.

Thus it must be admitted that the enigma of cardiac dyspnea remains, with perhaps one less veil persisting to obscure our view of the subject. The work of breathing is obviously increased in congestive heart failure because of decreased absolute compliance. Whether this is due to a reduction in the number of elastic fibers available for ventilatory excursions, the reduced availability of a given number of fibers or altered physical properties of the fibers is difficult to determine. However, it has been shown that when pulmonary capillary pressure is reduced by mitral valvulotomy, dyspnea is relieved though compliance and vital capacity is reduced. This observation would indicate that increased "PC" pressure is just one more factor which may contribute to a patient's subjective sensation of dyspnea, though the intrinsic physical properties of the lungs may remain unchanged.

\section{SUM MARY}

1. Pulmonary compliance was found to be below normal in all thirty patients with heart disease studied by the esophageal balloon technique.

2. Pulmonary "capillary" pressure was elevated above normal in sixteen of the nineteen patients in whom pulmonary vascular pressures were measured by cardiac catheterization.

3. Dynamic studies before, during, and after exercise showed a clear correlation of the degree of decreased compliance with the degree of elevation of "PC" pressure in six of the nine cardiac patients studied in this way. In the three others compliance remained constant in the face of elevated "PC" pressures.

4. Compliance was also found to be reduced in five patients after mitral valve surgery, as compared with their preoperative values, at a time when dyspnea was considerably improved and "PC" pressures have usually been reduced.

5. No consistent relationship was found between pulmonary compliance and increased pulmonary vascular pressures, pulmonary blood flow or pulmonary arteriolar resistance. Compliance was, however, found to be directly proportional to vital capacity. 


\section{ACKNOWLEDGMENTS}

The authors wish to thank Dr. James L. Whittenberger for his encouragement to pursue this study and Dr. Jere Mead for his reassurance in the techniques used. We also wish to thank Dr. Elliot Rapaport and Dr. Lawson McDonald for their assistance with the cardiac catheterizations.

\section{REFERENCES}

1. Peabody, F. W., and Wentworth, J. A., Clinical studies of the respiration. IV. The vital capacity of the lungs and its relation to dyspnea. Arch. Int. Med., 1917, 20, 443.

2. Christie, R. V., and Meakins, J. C., The intrapleural pressure in congestive heart failure and its clinical significance. J. Clin. Invest., 1934, 13, 323.

3. Mack, I., Grossman, M., and Katz, L. N., The effect of pulmonary vascular congestion on the distensibility of the lungs. Am. J. Physiol., 1947, 150, 654.

4. Heyer, H. E., Holman, J., and Shires, G. T., The diminished efficiency and altered dynamics of respiration in experimental pulmonary congestion. Am. Heart J., 1948, 35, 453.

5. Borden, C. W., Ebert, R. V., Wilson, R. H., and Wells, H. S., Studies of the pulmonary circulation. II. The circulation time from the pulmonary artery to the femoral artery and the quantity of blood in the lungs in patients with mitral stenosis and in patients with left ventricular failure. J. Clin. Invest., 1949, 28, 1138.

6. Lagerlöf, H., Werkö, L., Bucht, H., and Holmgren, A., Separate determination of the blood volume of the right and left heart and the lungs in man with the aid of the dye injection method. Scandinav. J. Clin. \& Lab. Invest., 1949, 1, 114.

7. Kopelman, H., and Lee, G. de J., The intrathoracic blood volume in mitral stenosis and left ventricular failure. Clin. Sc., 1951, 10, 383.

8. Mead, J., Frank, N. R., Lindgren, I., Gaensler, E. A., and Whittenberger, J. L., A technic for the measurement of pulmonary compliance and resistance: Its application to normal patients and patients with mitral stenosis. Clin. Res. Proc., 1953, 1, 116.

9. Brown, C. C., Jr., Fry, D. L., and Ebert, R. V., The mechanics of pulmonary ventilation in patients with heart disease. Am. J. Med., 1954, 17, 438.

10. McIlroy, M. B., and Christie, R. V., The work of breathing in emphysema. Clin. Sc., 1954, 13, 147.
11. Rohrer, F., Der Strömungswiderstand in den menschlichen Atemwegen und der Einfluss der unregelmässigen Verzweigung des Bronchialsystems auf den Atmungsverlauf in verschiedenen Lungenbezirken. Arch. f. d. ges. Physiol., 1915, 162, 225.

12. v. Neergaard, K., and Wirz, K., Utber eine Methode zur Messung der Lungenelastizität am lebenden Menschen, insbesondere beim Emphysem. Ztschr. klin. Med., 1927, 105, 35.

13. Bayliss, L. E., and Robertson, G. W., The viscoelastic properties of the lungs. Quart. J. Exper. Physiol., 1939, 29, 27.

14. Dayman, H., Mechanics of airflow in health and in emphysema. J. Clin. Invest., 1951, 30, 1175.

15. Mead, J., and Whittenberger, J. L., Physical properties of human lungs measured during spontaneous respiration. J. Applied Physiol., 1953, 5, 779.

16. DuBois, A. B., Botelho, S. Y., and Comroe, J. H., Jr., A new method for measuring airway resistance in man using a body plethysmograph: values in normal subjects and in patients with respiratory disease. J. Clin. Invest., 1956, 35, 327.

17. Buytendijk, H. J., Electrische Drukkery. Groningen, Oppenheim, 1949.

18. Mead, J., and Gaensler, E., Federation Proc., In press.

19. Fry, D. L., Stead, W. W., Ebert, R. V., Lubin, R. I., and Wells, H. S., The measurement of intraesophageal pressure and its relationship to intrathoracic pressure. J. Lab. \& Clin. Med., 1952, 40, 664.

20. Cherniack, R. M., Farhi, L. E., Armstrong, B. W., and Proctor, D. F., A comparison of esophageal and intrapleural pressure in man. J. Applied Physiol., 1955, 8, 203.

21. Dexter, L., Haynes, F. W., Burwell, C. S., Eppinger, E. C., Seibel, R. E., and Evans, J. M., Studies of congenital heart disease. I. Technique of venous catheterization as a diagnostic procedure. J. Clin. Invest., 1947, 26, 547.

22. Hellems, H. K., Haynes, F. W., and Dexter, L., Pulmonary 'capillary' pressure in man. J. Applied Physiol., 1949, 2, 24.

23. Dexter, L., Pathologic physiology of mitral stenosis and its surgical implications. Bull. New York Acad. Med., 1952, 28, 90.

24. Frank, R. N., Mead, J., Siebens, A. A., and Storey, C. F., Measurements of pulmonary compliance in seventy healthy young adults. J. Applied Physiol., In press. 